\title{
The inhibitory effects of an observer on instrumental aggression*
}

\author{
MAX C. DERTKE, LOUIS A. PENNER, \\ HAROLD L. HAWKINS, and CONCHITA SUAREZ $\dagger$ \\ University of South Florida, Tampa, Fla. 33620
}

The purpose of this study was to investigate the effect of explicit threat of retaliation and guilt on instrumental aggression. Thirty undergraduate females were assigned randomly to one of the three following conditions: (1) no retaliation, (2) retaliation, or (3) no-retaliation/ observer present. Each $\mathrm{S}$ supposedly delivered electric shock to a victim (actually a confederate) for 20 trials. Post hoc comparisons of all means disclosed significantly less aggression in Conditions 2 and 3 than in Condition 1 . The inhibitory effect of retaliation was consistent with Penner \& Hawkins's (1971) findings. Rosenberg's (1965) concept of evaluation apprehension was used to explain the effect of the observer.

Laboratory studies of aggression can be assigned to two nonmutually exclusive categories: (1) aggression produced by some motivational state, such as anger or frustration (e.g., Baron, 1971) and (2) aggression produced by commands, instructions, or rewards given by an "authority" (e.g., Milgram, 1963). Buss (1971) has labeled the behavior that results from the former situations "angry aggression" and from the latter "instrumental aggression." By using the term instrumental aggression, Buss calls attention to the fact that these aggressive acts are means to some end rather than being ends in themselves. The present study investigated the effects of certain situational variables in an instrumental aggression situation.

Penner \& Hawkins (1971) investigated instrumental aggressivity as a function of (a) visual contact between victim and aggressor and (b) victim identification of the aggressor. In their study, aggression was found to be inhibited by aggressor identification but not affected by visual contact, i.e., aggressive behavior was not attenuated when aggressors were in visual contact with victims unless the aggressor was labeled. Penner and Hawkins posited that the "... inhibitory influences of harmer identification may have had its origin in the harmer's social learning history [1971]." That is, they proposed that their Ss may have learned from prior social interactions that aggressive activity against others is "... more apt to produce retaliation in cases where the victim knows his harmer than when the harmer is

\footnotetext{
*This research was supported by a grant to the second author from the Office of Sponsored Research, University of South Florida, Tampa, Florida 33620. Dewey Rundus sponsors the Florida, Tampa, Florida 33620 . Dewey Rundus
article and takes full editorial responsibility for it.

fOrder of authorship was determined by chance. Reprint requests should be addressed to Dr. L. A. Penner, Department of Psychology, University of South Florida, Tampa, Florida 33620.
}

anonymous." The expectation of retaliation is thought to operate as an inhibitor, even when the situation contains no explicit retaliation threat.

An alternative explanation of the Penner and Hawkins findings was that "guilt" rather than fear of retaliation was producing the observed effect. While it is likely that fear of retaliation and guilt produced by aggressive behavior have common origins, it would be appealing to separate these factors and assess their relative influence. In an attempt to do this, Penner and Hawkins (unpublished data) replicated their 1971 study and added a condition in which the harmer's peers (other Ss who could also harm the victim) knew that the $S$ was the harmer on a given trial. It was found that peer identification, the hypothesized "guilt" condition, had no effect upon aggressive behaviors. Several explanations of this finding can be offered: (1) guilt does not inhibit aggression, (2) being identified as a harmer to people other than the victim does not produce "guilt," or (3) due to the fact that observing peers were also potential harmers, the Ss may have experienced no guilt, i.e., the Ss may have felt that their peers were in no position to judge them negatively, since they were as "guilty" as the S. It was in order to assess the tenability of this third interpretation that the present study was conducted.

The experiment compared three conditions: (1) a retaliation condition, wherein aggressor Ss were told that they would be required to exchange roles with the victim during a subsequent stage of the experiment, (2) a no-retaliation condition, where Ss were told that they would not be victims, and (3) a no-retaliation condition in which an observer identified as one who would be neither aggressor nor victim was present. Ss were told that the experiment was a study of physiological reactions to stress and that a variety of body reactions would be measured. Two measures of aggression-the intensity and duration of electric shock supposedly delivered to an accomplice "victim" by S-were obtained.

\section{METHOD \\ Design}

Ss were assigned randomly to one of three conditions of the experiment. In the retaliation condition, naive Ss were told that, after administering 20 electric shocks to another $\mathrm{S}$, the administrator-recipient roles would be reversed. In the no-retaliation condition, naive Ss were told that they were to administer 20 electric shocks to another $S$; role reversal was not mentioned. In the no-retaliation/observer condition, Ss were told to administer 20 shocks to another $\mathrm{S}$ while a third $\mathrm{S}$ observed; role reversals were not mentioned. Ten naive $S s$ were assigned to each condition and, in all cases, the "victims" and observers were confederates of $\mathrm{E}$. 
Table 1

Arithmetic Mean Aggression Scores (Intensity by Duration of Shock) as a Function of Retaliation, No Retaliation, and Observer Presence

\begin{tabular}{lccc}
\hline & $\begin{array}{c}\text { Retali- } \\
\text { ation } \\
(\mathrm{N}=10)\end{array}$ & $\begin{array}{c}\text { No } \\
\text { Retali- } \\
\text { ation } \\
(\mathrm{N}=10)\end{array}$ & $\begin{array}{c}\text { No Retalia- } \\
\text { tion/Observer } \\
\text { Present } \\
(\mathrm{N}=10)\end{array}$ \\
\hline Mean & .78 & 2.4 & .88 \\
SD & .90 & 2.55 & 1.07 \\
\hline
\end{tabular}

\section{Subjects}

Thirty female undergraduates enrolled in introductory psychology at the University of South Florida participated in the experiment. They earned extra credit points for participation.

\section{Apparatus}

The equipment consisted of one standard timer, two voltage meters, a display-response panel, a pair of finger electrodes, and three sets of "physiological sensing electrodes." The standard electric timer and one voltage meter were in a room adjoining the experimental room. These were used by the $\mathrm{E}$ to monitor the intensity and duration of the shock supposedly delivered to the victim. The second voltage meter was placed in the experimental room in a position where voltage readings were visible to the victim (a confederate) but not to the actual $\mathrm{S}$, the harmer. A light attached to the voltage meter was illuminated when shock was supposedly initiated by the harmer. The function of this item of equipment was to inform the victim of the intensity (from the voltage meter) and duration (from the light which stayed on for the shock duration) of the supposed shocks. Ss were not aware of the function of this piece of apparatus. Also located in the experimental room and directly in front of the $S$ was the display-response panel. It contained four features: (1) six "shock intensity level" switches and a reset button; (2) an additional voltage meter which, like the other two voltage meters, was wired in parallel with the shock intensity level buttons in order to provide a visual display of shock level selected by the S; (3) a 5-sec clock with a sweep hand that moved backward to $0 \mathrm{sec}$ when activated; and (4) a response button which, when depressed by $S$, supposedly initiated shock. A low wooden barrier divided the table and separated the harmer and victim; the barrier permitted visual contact between harmer and victim but prevented direct view of the other's equipment.

\section{Procedure}

The naive $\mathrm{S}$ and confederate (or confederates, as in the no-retaliation/observer condition) reported to the experimental room, where it was explained that the research project was a study of physiological reactivity to a variety of stress-producing situations. Ss were told that their GSR, heart rate, and respiration rate would be recorded by $\mathrm{E}$ as they administered electric shocks to someone, received shocks, or observed shock administration. It was further explained that the shock levels being utilized were aversive but not dangerous and that Ss in each of the roles were to "react naturally." Questions were answered and roles were decided by a drawing of lots, prearranged so that the naive $S$ was always selected to be the harmer. In the no-retaliation and no-retaliation/observer conditions, Ss were told that the experiment would terminate after 20 trials. In the retaliation condition, Ss were told that the harmer-victim roles would be reversed for 20 additional trials. After the faked drawing, the participants were seated in the experimental room, the "physiological sensing electrodes" were attached, and the shock elecirodes were placed upon the victim's index finger. The observer was positioned in an elevated chair in the experimental room. This allowed her to see the harmer and the victim and all of their responses. After the function of the apparatus was explained, five practice trials with shock absent were conducted. It was explained that the harmer was to select one of the six shock intensity levels before each trial and then, after a verbal "ready" signal, to watch the 5-sec clock for the activation of the shock apparatus. Harmers were told that they could press the response button at any time during the 5-sec travel of the clock's sweep hand and that by so doing they would administer shock to the victim for the remainder of the 5-sec interval at the intensity level that they had preselected. Following practice, the 20 experimental trials were conducted. Each trial began by S "clearing" the panel by pressing the reset button, which set the clock to $5 \mathrm{sec}$ and raised the intensity switch closed on the previous trial. S then selected a shock level and waited for the "ready" signal. After .5-1.5 sec, the clock hand started to move toward zero, with shock supposedly administered when the $S$ pressed the response button. The $\mathrm{E}$ communicated with participants via a one-way intercom system. Following the completion of 20 trials, Ss in all conditions were debriefed. The debriefing was used to determine whether Ss had suspected the true purpose of the experiment and allay any concerns Ss might have had about administering shock.

\section{RESULTS}

An "aggression score" was computed for each $\mathrm{S}$ in each condition of the experiment by multiplying shock intensity on each trial by shock duration and averaging this product over the 20 trials (Baron \& Eggleston, 1972). The mean and standard deviation of the aggression scores across $\mathrm{Ss}$ in each condition are presented in Table 1 .

A randomized groups analysis of variance (Winer, 1962) was performed on the aggression scores. This analysis revealed an overall treatment effect $(F=2.88$, $\mathrm{df}=1 / 27, \mathrm{p}<.07)$. Comparisons between group means were made using Fisher's LSD (Kirk, 1968), which disclosed that aggression scores under the no-retaliation condition were significantly higher $(p<.05)$ than under either of the two other conditions (LSD = 1.52). The observed difference between the retaliation and the no-retaliation/observer condition was not found to be statistically reliable.

The postexperimental debriefing revealed that no Ss were aware of the true purpose of the experiment and that the reasons given for the study were accepted.

\section{DISCUSSION}

The results of this study strongly suggest that the simple presence of an observing third party may inhibit aggressivity almost as effectively as the fear of retaliation. Why does the observer inhibit aggression? The construct of "guilt" is a somewhat imprecise explanation and needs further explication. Rosenberg's (1965) concept of evaluation apprehension may provide this. As it was originally used, evaluation apprehension referred to Ss' anxiety in an experiment due to their feelings that E would be evaluating them as to emotional adequacy, mental health, and moral fiber. In the present instance, the observer may have, in the Ss' view, filled the role of an evaluator. The observer was placed so that she had a clear view of the S's display-response console. Thus, the $S$ may have felt that, in addition to the observer's explicitly specified role in the experiment, she might have been evaluating or passing judgment on the $S$. The $S$ would have then been placed in conflict between the instructions given by $\mathrm{E}$ and her desire to look good (or moral) to the observer. The strategy thus adopted by Ss was to shock the victim, but at lower intensities and for shorter 
durations than Ss in the experimental situation where there was no observer present.

\section{REFERENCES}

Baron, R. A. Magnitude of victim's pain cues and level of prior anger arousal as determinants of adult aggressive behavior. Journal of Personality \& Social Psychology, 1971, 3, 236-243.

Baron, R. A., \& Eggleston, R. J. Performance on the aggression machine: Motivation to help or harm. Psychonomic Science, 1972, 26, 321-322.

Buss, A. H. Aggression pays. In J. L. Singer (Ed.), The control of aggression and violence. New York: A cademic Press, 1971.
Kirk, R. E. Experimental design: Procedures for the behavioral science. Belmont, Calif: Brooks/Cole, 1968.

Milgram, S. Behavioral study of obedience. Journal of Abnormal \& Social Psychology, 1963, 24, 279-287.

Penner, L. A., \& Hawkins, H. L. The effects of visual contact and aggressor identification on interpersonal aggression. Psychonomic Science, 1971, 24, 261-263.

Rosenberg, M. J. When dissonance fails: On eliminating evaluation apprehension from attitude measurement. Journal of Personality \& Social Psychology, 1965, 28, 39-63.

Winer, B. J. Statistical principles in experimental design. New York: McGraw-Hill, 1962.

(Received for publication November 8, 1972.) 